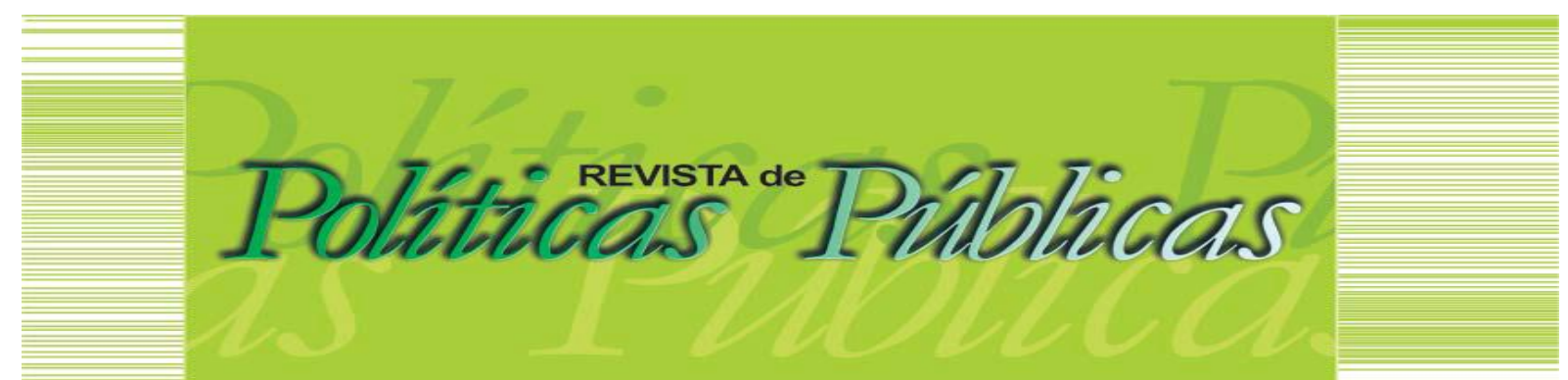

\title{
POLÍTICAS PÚBLICAS DE ATENÇÃO À SAÚDE INDÍGENA NO BRASIL: contribuição a um debate permanente
}

\author{
Daniele Gruska Benevides Prata ${ }^{1}$ \\ João Tadeu de Andrade²
}

\section{Resumo}

Os povos indígenas brasileiros estão entre os segmentos da população em maioria, pois são vítimas desde o período da colonização de violências das mais diversas. A Constituição Federal de 1988 trouxe a adoção de medidas protetivas aos povos indígenas e de direitos diferenciados, como a saúde. Este artigo tem o objetivo de compreender como funciona a saúde indígena e quais seus mecanismos regulatórios, com base em pesquisa bibliográfica e documental em publicações disponíveis no Portal da CAPES e em outras fontes. Usa os descritores "saúde indígena", "políticas públicas de saúde indígena" e "Lei Arouca". Seleciona publicações que tratavam do assunto desde 1999 até o ano de 2019. Um dos principais desafios, conforme esta reflexão, é aliar a medicina ocidental aos princípios das etnomedicinas, possibilitando um atendimento de qualidade para os povos.

Palavras-chave: Saúde Indígena. Políticas Públicas de Saúde Indígena. Medicina Tradicional Indígena. Direitos Garantidos.

\section{PUBLIC POLICIES FOR THE ATTENDANCE OF INDIGENOUS HEALTH IN BRAZIL: contribution to a permanent debate}

\begin{abstract}
Brazilian indigenous peoples are among the largest segments of the population, as they have been victims since the period of colonization of the most diverse types of violence. The Federal Constitution of 1988 brought the adoption of protective measures to indigenous peoples and differentiated rights, such as health. This article aims to understand how indigenous health works and what its regulatory mechanisms are, based on bibliographic and documentary research in publications available on the CAPES Portal and other sources. The descriptors "indigenous health", "public indigenous health policies" and "Lei Arouca" were used. This article selected publications that dealt with the subject from 1999 to 2019. One of the main challenges, according to this reflection, is to combine Western medicine with the principles of ethnomedicines, enabling quality care for people.
\end{abstract}

Keywords: Indigenous Health. Public Indigenous Health Policies. Traditional Indigenous Medicine. Guaranteed Rights.

Artigo recebido em: 28/01/2020 Aprovado em: 28/10/2020 DOI: http://dx.doi.org/10.18764/2178-2865.v24n2p878-897.

\footnotetext{
${ }_{1}$ Psicóloga e Enfermeira. Mestre em Administração pela Universidade de Fortaleza e Doutoranda em Políticas Públicas pela Universidade Estadual do Ceará. Enfermeira Assistencial na Clínica Cirúrgica do Complexo Hospitalar da UFC - Hospital Universitário Walter Cantídio. E-mail: daniprata31@gmail.com

${ }^{2}$ Bacharel em Ciências Sociais. Doutor em Antropologia pela Universidade Federal da Bahia. Professor associado da Universidade Estadual do Ceará. E-mail: joao.andrade@uece.br
} 


\section{INTRODUÇÃO}

O presente artigo constitui parte de pesquisa de doutorado na Pós-graduação em Políticas Públicas da Universidade Estadual do Ceará - UECE. Seu propósito é compreender de que forma as políticas públicas de atenção à saúde indígena tem se efetivado e quais seus alcances e limites na relação com a Medicina Tradicional Indígena. Sabemos que a população indígena brasileira não se constitui como um todo homogêneo. Cada etnia possui particularidades decorrentes do ecossistema em que habita, da cultura, dos meios de produção e de elementos como a interação com outros povos. A concepção de saúde, de doença e os métodos de cura também são construções que variam de etnia para etnia, mesmo que muitas das técnicas conhecidas e adotadas também sejam admitidas e realizadas por outros grupos, inclusive os não indígenas.

0 grande diferencial da medicina tradicional indígena diz respeito à concepção de ser humano integrado à natureza e analisado de forma holística, o que requer uma apreciação dos processos de saúde e doença decorrentes de múltiplos fatores, inclusive de ordem espiritual e existencial. Dessa forma, na perspectiva dos indígenas, as curas são efetivadas com o uso de uma metodologia diferente da medicina ocidental, priorizando o uso de recursos naturais e com orientações para o cuidado com a saúde a partir de uma visão holística e integrada com o ecossistema.

Este artigo, enquanto esforço teórico e conceitual, tem o escopo de contribuir para o exame da formulação, implementação e atual situação da saúde indígena no Brasil. As políticas públicas neste setor são orientadas por um conjunto de leis e normatizações que foram geradas a partir das inquietações das entidades que apoiam a luta indígena e por reivindicações das diversas etnias que compõem a população indígena brasileira. Os programas e serviços de saúde para a população brasileira são dirigidos pelo Sistema Único de Saúde - SUS, e pelas orientações do Ministério da Saúde - MS. Complementando o SUS, para a população indígena existe a lei Arouca e portarias decorrentes dela. A referida lei e as portarias apontam as diretrizes do que está garantido na Constituição Federal de 1988, gerando ações que se traduzem em Políticas Públicas de Saúde Indígena. Elas se apresentam com características diferentes de outros programas de saúde, tanto pelas especificidades da população, como também pelo que está avalizado nas leis.

Como estratégia metodológica, realizamos uma pesquisa bibliográfica e documental, com análise crítica de leis, portarias e documentos que regulamentam e orientam as Políticas Públicas de Saúde Indígena; em acréscimo procedemos ao exame deste processo fazendo uso de publicações acadêmicas encontradas no Portal da Coordenação de Aperfeiçoamento de Pessoal de Nível Superior - CAPES. Assim, foi conduzido um trabalho de apreciação crítica das publicações que tratam dos 
mecanismos regulatórios da saúde indígena e a correspondente avaliação destes dispositivos. Para selecionar as publicações usamos os descritores "saúde indígena", "políticas públicas de saúde indígena" e "Lei Arouca". Foram identificadas 30 publicações desde a implantação dos Distritos Sanitários Especiais Indígenas - DSEI em 1999, até o ano de 2019, que contemplam como a saúde indígena é idealizada, suas formas de funcionamento e a avaliação da eficácia de seus programas. Os demais documentos colhidos foram acessados nos sítios do MS, FUNAI e nas publicações de organizações de apoio à luta indígena, como a Articulação dos Povos Indígenas do Brasil - APIB, Conselho Indigenista Missionário - CIMI e Instituto Socioambiental - ISA.

Com base nos dados coletados, sustentamos que, apesar de muitas lutas, os povos indígenas ainda sofrem com a falta de recursos e desrespeito a suas práticas culturais (religiosas, alimentares, de saúde, educacionais etc.). Embora a legislação seja clara e garanta direitos diferenciados, medidas básicas sequer são atendidas, como, por exemplo, o respeito à medicina tradicional indígena e uma equipe de saúde especializada nas particularidades de cada etnia. Os desafios para efetivação dos programas e da autonomia de escolha dos índios para a destinação de recursos à saúde são inúmeros, precisando ser observados como um franco desrespeito às leis, aos acordos e tratados nacionais e internacionais.

Embora este artigo se configure como uma restrita revisão de literatura, os achados já denunciam um forte descaso com os povos indígenas, em especial aos aspectos de sua saúde, que envolvem questões de ordem dos recursos estatais, como também do respeito a suas crenças e métodos de cura.

\section{POLÍTICAS PÚBLICAS COMO GARANTIAS CONSTITUCIONAIS}

As políticas públicas são ações desenvolvidas pelos governos que impactam diretamente a vida dos cidadãos. Essas ações são desencadeadas por problemas sociais que precisam ser solucionados e que possuem causas multifatoriais, como também desdobramentos múltiplos. Dentre as atividades que podem estar associadas às políticas públicas, estão aquelas que trazem impactos de curto, médio e longo prazo e estão localizadas nas áreas em que o Estado atua, ou seja, em tudo que é controlado ou recebe influência dos governos ${ }^{1}$ (GIOVANELLA et al, 2012).

As políticas de saúde estão dentre as ações do governo que possuem um viés de longo prazo. Isso porque a erradicação e controle de doenças e as medidas preventivas não podem ser visualizadas em curtos períodos, pois requerem a avaliação de diversos indicadores e a análise de séries históricas para serem quantificadas. 
Dependendo do objetivo do governo e da importância dada aos mecanismos preventivos da saúde, os investimentos nas agendas de saúde e acompanhamento de grupos notadamente vulneráveis para o adoecimento é realizado. No caso brasileiro, a constituição é clara quanto a isso, sobretudo quando o grupo é formado por pessoas em situação de vulnerabilidade ou com direitos diferenciados, como os indígenas.

A CF de 1988, de acordo com 0 artigo 196, garante à população 0 acesso à saúde de forma gratuita, universal e integral para todos os cidadãos, sem discriminação².

Artigo 196: A saúde é direito de todos e dever do Estado, garantido mediante políticas sociais e econômicas que visem à redução do risco de doença e de outros agravos e ao acesso universal e igualitário às ações e serviços para sua promoção, proteção e recuperação (BRASIL, 1988).

Mesmo que a lei estabeleça a obrigatoriedade do Estado para atender de forma equânime os cidadãos, na prática uma lacuna na abrangência do SUS ${ }^{3}$, de acordo com o que preconiza a lei, pode ser observada. Garnelo (2012, p.23) aponta que: "Na forma original como o SUS foi concebido, a população indígena não representava uma de suas prioridades, posto que à época, a prestação de cuidados à saúde desses grupos ainda estava sob responsabilidade do órgão indigenista".

Em outras palavras, as ações que são visualizadas como políticas públicas ocorrem de acordo com o que está fundamentado na lei, mas está intimamente relacionado com os interesses políticos de quem legisla e dos grupos que se constituem como dominantes na sociedade, o que pode, inclusive, prejudicar a adesão do que é entendido como direito de um povo.

A negligência de atendimento para os povos indígenas, seja em qualquer área das políticas públicas, é uma realidade. Notadamente é uma população que fica excluída das ações estatais porque se configura como uma ameaça ao capital, em virtude dos direitos e garantias que constam na Constituição Federal.

Nesse caso dos indígenas, por serem grupos minoritários e estarem em condições para obterem direitos diferenciados, as decisões sobre políticas especiais restritas a estes grupos são deliberadas em conferências locais, regionais, estaduais e nacionais, possibilitando a participação de diversas etnias e colocando em pauta as particularidades dos povos (SMANIO, 2013).

Mesmo com essa ferramenta importante de participação popular, muitas das decisões ficam a cargo do governo, que resolve ou não acatar as deliberações para a realização de investimentos. As diversas etnias e as organizações de movimentos sociais de proteção aos povos indígenas precisam sempre estar alertas quanto à adoção de medidas estatais que não corroboram os direitos e garantias. 


\section{POLIITICAS PÚBLICAS DE SAÚDE INDÍGENA E OS DIREITOS DIFERENCIADOS}

A saúde indígena é considerada também uma garantia constitucional, pois a saúde pública é direito de todos e dever do Estado. Na medida em que a saúde pública, de acordo com a Constituição Federal de 1988, foi fundamentada em princípios pautados na justiça social e no acesso integral e universal aos recursos, algumas ações diferenciadas precisaram ser idealizadas, uma vez que alguns grupos étnicos ou com vulnerabilidade se encontram em constante situação de desigualdade e exclusão. As medidas corretivas precisam ser edificadas, como condição para a promoção de uma tentativa de simetria entre os diferentes sujeitos que compõem a nação brasileira, nas suas mais peculiares especificidades (MARTINS, 2013).

A partir desses pilares, o setor público de saúde no Brasil fundamenta suas atuações, conduzindo programas que sejam necessários para os distintos grupos populacionais, com características epidemiológicas diversas. Os grupos, com particularidades socioeconômicas, inclusive podem receber atenção caracterizada do Estado em decorrência das suas condições e necessidades (SOUZA, 2003).

Souza (2003) assinala que o programa de saúde brasileiro precisa ofertar de acordo com as indigências regionais, epidemiologia, condições ambientais, miscigenação, particularidades étnicas, dieta, meios de produção, saneamento, moradia, escolaridade etc. ações que sejam compatíveis com suas especificidades e, de fato, conduzam a saúde de acordo com o que preconiza a Organização Mundial de Saúde - OMS. Assim, a saúde deve ser compreendida como um todo complexo que tem bases da prevenção, mas que deve, também, promover os tratamentos para cura de forma digna e que leve em consideração os sistemas culturais que constituem a diversidade dos povos.

Por sua vez, Zaluar (1997) aponta que os mais pobres, obviamente, necessitam de ações em mais âmbitos, como por exemplo, no campo do saneamento e da alimentação. Aqueles, tais como os indígenas, que se encontram em situação vulnerável, possuem tática de prevenção e tratamento de enfermidades utilizando seus recursos naturais, entretanto, por questões que envolvem a pobreza e a exclusão, podem ter esses mecanismos adaptados, constituindo estruturas de enfrentamento para debelar as doenças, através de ritos espirituais, medicações caseiras e cuidados populares em saúde.

Partindo disso, há a necessidade premente de adoção de metodologias de participação popular, efetivando as ações de exercício de cidadania e de legitimação das práticas de saúde dos 
diversos grupos populacionais, permitindo a adoção de medidas a partir da escuta de representantes desses grupos que especialmente não conseguem a representação política (BEM, 2014).

Os indígenas estão dentro desse grupo que se configura como minoria, com pouca ou nenhuma representação nas esferas do poder, que se encontra em condições de extrema pobreza, vulnerabilidade e com direitos frequentemente ameaçados pelos grupos dominantes (SOUZA, 2017).

Entre os anos de 1986 e 1999, diversas conferências e encontros (como a Conferência Nacional de Saúde e Encontros de Entidades de Classe) sobre saúde pública, organizadas pelos movimentos sociais, entidades de classe e pelo próprio governo, possibilitaram a estruturação e reestruturação do setor da saúde indígena. Nesses eventos os índios passaram a exigir a participação nas deliberações sobre aspectos da sua saúde, inclusive no que tange à autonomia e ao respeito a elementos culturais de sua identidade étnica. Um dos marcos mais importantes nesse longo processo foi a Lei Arouca (9836), publicada em 1999, que entrou em vigor apenas em 2002. De acordo com a referida Lei:

Art. 19-F. Dever-se-á obrigatoriamente levar em consideração a realidade local e as especificidades da cultura dos povos indígenas e o modelo a ser adotado para a atenção à saúde indígena, que se deve pautar por uma abordagem diferenciada e global, contemplando os aspectos de assistência à saúde, saneamento básico, nutrição, habitação, meio ambiente, demarcação de terras, educação sanitária e integração institucional.

Como decorrência da Lei Arouca, um grande avanço na saúde indígena foi a criação de unidades que reconhecessem a heterogeneidade dos povos tradicionais. Assim, os DSEI que levariam em consideração, além de posição geográfica, as línguas faladas e os recursos naturais disponíveis, foram concebidos, sendo implantado como piloto o Distrito Sanitário Yanomâmi. Na medida em que as ações no projeto piloto se exibiam como prósperas, os demais distritos foram idealizados (ARAÚJO, 2012).

No decorrer das experiências nas diversas etnias, durante os estudos que se pautam desde a implantação do programa piloto em 1999 até a fundação dos 34 distritos, ocorrida ao final do ano 2000, percebeu-se a necessidade de valorizar o agente de saúde indígena, que deveria obrigatoriamente fazer parte da etnia atendida. Essa função pode ser compreendida por uma dupla responsabilidade: de fortalecimento do elo entre os povos e as políticas públicas indigenistas no campo da saúde e a defesa das práticas tradicionais de medicina indígena, adotadas pela etnia atendida (GARNELLO; SAMPAIO, 2005).

No mesmo ano da publicação da Lei Arouca, a Fundação Nacional de Saúde - FUNASA, antes responsável pela pauta da saúde indígena, viabilizou um pacto de prestação de serviços para os povos indígenas, colocando em prática um dos pilares do SUS: a descentralização. Desta forma, para 
atingir uma maior cobertura populacional e atender as demandas das mais diferentes culturas, fundações, ONGs e outras entidades ligadas ao movimento indígena poderiam ofertar os serviços necessários para a implementação das políticas públicas de saúde, em especial nas localidades de difícil acesso (GARNELO; SAMPAIO, 2005).

Garnelo (2012) aponta que a terceirização pode ser criticada como uma espécie de precarização do serviço de saúde aos povos indígenas, porém a indisponibilidade de profissionais e entidades para atuação em locais de difícil acesso acaba por justificar a forma como o serviço tem sido oferecido. Em outras palavras, significa que se não for da forma como vem sendo conduzida, a agenda de saúde acabaria desaparecendo por completo em virtude da falta de prestadores habilitados para atuar nas áreas.

A justificativa para a terceirização, então, é a possibilidade de atendimento, já que a principal crítica sobre agendas de saúde se pauta na descontinuidade das ações e as dificuldades de alimentar sistemas de indicadores que viabilizassem o controle de dados epidemiológicos para planejamentos futuros. Em contrapartida, as dificuldades materiais e humanas do Estado inviabilizavam a oferta dos serviços para a população, que, mesmo precariamente, recebia alguma atenção pela via terceirizada.

Outra análise também pautava as discussões sobre esse processo de terceirização e dizia respeito à dupla função de fornecedor e fiscal exercida pelas entidades que estavam relacionadas ao movimento indígena. Os grupos que deveriam atuar na defesa dos direitos passaram a representar 0 próprio governo, inviabilizando o seu papel de críticos.

Cardoso (2015) elucida que estão distribuídos em todo o território nacional 34 DSEI. As referidas estruturas fazem a cobertura da população indígena, atentando para peculiaridades como ocupação geográfica, línguas faladas, etnias e questões culturais. Os DSEI possuem em sua estrutura Postos de Saúde, carros exclusivos para atender as demandas das aldeias, Polos Bases e Casas de Saúde Indígena, divididos estrategicamente por critérios territoriais e não, necessariamente, por estados, tendo como base a ocupação geográfica das comunidades indígenas.

Por seu turno, Ferreira, Portillo e Nascimento (2013) esclarecem que, para viabilizar essa atenção aos povos indígenas, a Secretaria Especial de Saúde Indígena - SESAI e os DSEI possuem uma estrutura colegiada que atua por meio de conselhos. Assim, o Controle social na Saúde Indígena é efetivado nas esferas nacional, estadual e municipal, o que permite a participação mais ativa das diversas etnias, possibilitando a fiscalização da destinação de recursos e da implementação dos programas de saúde, baseado nas orientações publicadas pelo MS/SUS e nas resoluções produzidas no Conselho Nacional de Saúde - CNS. Desta forma, a comunidade indígena é parte integrante desse 
processo, pois pode participar ativamente das deliberações sobre os investimentos para promoção da saúde.

Todos os DSEI possuem um Conselho Distrital de Saúde Indígena - CONDISI, que tem como responsabilidades realizar a fiscalização das ações implementadas, debatendo e apresentando as particularidades de cada etnia e região, auxiliando a formulação de políticas para fortalecer a saúde e desenvolvimento de práticas que viabilizem a manutenção dos aspectos culturais.

Os CONDISI são reconhecidos como órgãos colegiados de caráter permanente e deliberativo, organizados no campo de cada DSEI e sua composição, de acordo com a Portaria 755/2012 do Ministério da Saúde, é a seguinte:

Art. $4^{\circ}$ Os Conselhos Distritais de Saúde Indígena, órgãos colegiados de caráter permanente e deliberativo, serão instituídos no âmbito de cada (DSEI/SESAI/MS) e terão a seguinte composição:

I - cinquenta por cento de representantes dos usuários, eleitos pelas respectivas comunidades indígenas da área de abrangência de cada (DSEI/SESAI/MS);

II - vinte e cinco por cento de representantes dos que compõem a força de trabalho que atua na atenção à saúde indígena no Distrito Sanitário Especial Indígena e em órgãos do Sistema Único de Saúde (SUS) que executam ações de apoio complementar no âmbito do (DSEI/SESAI/MS), todos eleitos pelos representados; $e$

III - vinte e cinco por cento de representantes dos governos municipais, estaduais, distrital, federal e prestadores de serviços na área de saúde indígena, conforme o caso, nos limites de abrangência de cada (DSEI/SESAI/MS), indicados pelos dirigentes dos órgãos que representam.

Mesmo com essa estrutura que se fundamenta na participação sobre a saúde dos povos indígenas, ainda é preciso avançar em diversos aspectos, principalmente no que diz respeito à defesa e respeito aos povos indígenas. 0 Estado brasileiro, no formato que adota as políticas públicas indígenas, em quaisquer âmbitos, se pauta numa ação de tutela, negligenciando a autonomia dos povos e sua capacidade de decisão sobre aspectos que lhes são importantes.

Cardoso (2014) comenta que a saúde indígena está longe dos indicadores da população nacional. Embora a nossa legislação aponte a obrigatoriedade dos direitos diferenciados em vários âmbitos, as dificuldades materiais e profissionais do Estado e as forças econômicas e políticas prejudicam a aplicação de ações que viabilizem a justiça social e a proteção dos direitos conquistados, mantendo esse grupo em constante ameaça.

A FUNAI, SESAI, CONDISI e outros órgãos que atuam na defesa dos interesses indígenas na saúde procuram, de forma conjunta com os movimentos sociais e entidades envolvidas na luta indígena, revisar e elaborar periodicamente políticas públicas para a intervenção nas aldeias, resguardando as particularidades étnicas. Os DSEl recebem orientações de atuação, buscando a preservação do patrimônio material e imaterial dos povos. Neste contexto, as equipes de saúde precisam concatenar suas intervenções a partir dos princípios da Medicina Tradicional Indígena e em 
conjunto com os recursos da medicina ocidental, sem, no entanto, reproduzir uma ou outra de forma ortodoxa (SANTOS, 2008).

Os debates nas conferências de saúde abordam também os conflitos entre saberes e a supremacia da medicina convencional, que versa os outros meios de prevenção e tratamento de doenças como subalternos, pois não considera os métodos construídos a partir de lógicas diferentes da biomedicina como aptos e com status científicos para serem adotados pelos médicos diplomados (CIMI, 2013).

De acordo com Andrade e Sousa (2016), as práticas de saúde tradicionais construídas pelos mais diferentes povos e grupos populacionais são taxadas como de baixa efetividade e sem aplicabilidade pelos profissionais; os mesmos acreditam apenas na indústria farmacêutica $O$ diálogo e a integração de saberes ficam prejudicados, principalmente em relação ao uso de recursos naturais e à eficácia dos diversos rituais praticados nas aldeias. Isso porque as crenças e a relação dos sujeitos com os seus cuidadores não podem ser rejeitadas como práticas terapêuticas, o que já é amplamente difundido pela psicologia e, no entanto, refutado pelos profissionais que admitem apenas o uso de fármacos para resolução de problemas, sejam eles físicos, psicológicos ou espirituais. Complementando, Carlos Júnior (2014) acentua que a perspectiva da medicina tradicional dos povos indígenas é holística e por isso não concebe o processo de cura e doença descontextualizado de outros aspectos da vida, como a sanidade e a espiritualidade.

Ferreira (2012), por sua vez, explica que é também de conhecimento das autoridades de saúde que a estrutura para a atenção devida às populações indígenas é extremamente precária, pois poucos profissionais estão qualificados para a atuação de acordo com as peculiaridades das diversas etnias, de forma a conhecer os recursos naturais empregados para aplicar a utilização de recursos de diferentes para tratar as enfermidades.

O problema da saúde indígena esbarra, assim, na questão organizacional (e, por isto também assistencial). Talvez por essa razão a questão organizacional tem precedido a assistencial do ponto de vista dos gestores, particularmente no que concerne à baixa resolutividade das ações em saúde nos distritos sanitários indígenas, marcadas por carências de profissionais habilitados para atender à população local; alta rotatividade dos profissionais em área; falta de recursos de infraestrutura e equipamentos para determinados procedimentos e ações operados pelos DSEls (CARDOSO, 2014, p. 864).

Moura (2016) destaca que para isso é importante repensar o papel dos profissionais que atuam nas áreas indígenas, de forma a estruturar qualificações que permitam a construção das políticas de forma adequada ao que preconiza a lei, garantindo a efetividade do respeito cultural e da atenção à saúde. 0 agente de saúde indígena, reconhecido pela sua função profissional, social e política, deve promover a construção de laços entre as equipes de saúde e a população atendida, 
respeitando as práticas tradicionais, mas também procurando os recursos mais adequados para atender as demandas dos índios com maior efetividade.

Dessa forma, a importância dos cadastramentos e acompanhamento das etnias em colaboração com outros órgãos, como a FUNAI, e a contribuição dos movimentos sociais se fazem importantes, no sentido de garantir a efetividade dos direitos e a construção de ações que impactem de forma importante o bem-estar das populações indígenas e, em particular, para a promoção de saúde. (CIMI, 2013)

Mesmo que as dificuldades operacionais e a qualificação de profissionais ainda sejam uma realidade, principalmente para 0 atendimento de populações em áreas mais desfavorecidas, estratégias de efetivação precisam ser construídas, com a finalidade de atender ao que a legislação exige (SANTOS, 2008).

A literatura sobre saúde indígena aponta que os investimentos estão aquém das necessidades deste grupo populacional, pois o acesso aos profissionais, mesmo da atenção básica, é incipiente. Ou como explica Garnelo (2012, p. 52):

[...] insuficiente para as necessidades da saúde indígena; além disso, ele é distribuído com muitas desigualdades, dado o baixo grau de descentralização dos recursos até os níveis locais onde são executados os serviços de saúde. Embora se tenha observado um incremento ao longo dos anos subsequentes à implantação dos DSEI, as difíceis condições de acesso às áreas indígenas tornam os custos operacionais muito elevados. Por outro lado, uma parte significativa do financiamento tem sido repassada diretamente aos municípios, os quais não atendem adequadamente às necessidades distritais.

Porém, essa atenção não pode ser exclusivamente pautada nos saberes e práticas de saúde da medicina ocidental. O grande desafio é aliar os conhecimentos e práticas para alcançar uma promoção de saúde, ofertando métodos e técnicas adequados, sem ferir as especificidades culturais e oportunizando o uso de recursos disponíveis da Medicina Tradicional dos mais diversos povos (SOUZA, 2017).

Doenças comumente tratadas com ervas e mudanças nos hábitos de vida, fruto dos saberes dos povos, podem ser adotados pelos profissionais de saúde que atendem nas áreas indígenas. Admitir a existência de outras formas de tratamento pode ser importante na manutenção da saúde e redução de indicadores de adoecimento. Além disso, o uso de recursos produzidos pelos próprios indígenas se configura como um artificio importante para a redução dos custos dos tratamentos de saúde, além de favorecer os aspectos culturais.

$O$ tratamento de gripes e resfriados, com plantas nativas e a extração dos seus componentes para a confecção de chás, lambedouros, garrafadas e outros produtos, podem ser reconhecidos também como atividade econômica, uma vez que a sua utilização não é feita apenas 
pelos indígenas, mas também procurada por pessoas preocupadas com os efeitos colaterais dos fármacos industrializados.

O uso de seivas para tratamentos de pele, gerado por fungos e micoses como frieira, escabiose, verrugas e outras afecções da epiderme, também costuma ser usado com êxito, evitando os conhecidos efeitos sistêmicos dos medicamentos industrializados, que possuem concentrações maiores dos extratos de plantas para combater um maior número de doenças.

\section{DESAFIOS PARA EFETIVAÇÃO DAS POLÍTICAS PÚBLICAS DE SAÚDE INDÍGENA}

Os estudos produzidos em vários campos se debruçam sobre a efetividade dos recursos para garantir a longevidade da população indígena. Indicadores construídos a partir de uma lógica da dualidade entre saúde e doença e da percepção do ser humano de forma segmentada, tal como preconiza uma orientação cartesiana, ainda imperam nas métricas dos sistemas de saúde em muitos países, notadamente os que fazem parte do ocidente. Tais indicadores partem do diagnóstico através de exames laboratoriais, de imagem e de evidências clínicas e não levam em consideração os aspectos psicológicos e espirituais das doenças (CARDOSO, 2014).

Diehl e Langdon (2015) esclarecem que, mesmo antes da SESAI, denúncias sobre a efetividade do que está garantido em lei e a suspeita de que recursos destinados para a saúde indígena estão sendo usados inadequadamente e desviados para outras finalidades têm chegado 0 Ministério Público. Uma parte dessas acusações está relacionada à privação de atendimento dos índios que habitam terras não demarcadas, deixando alguns grupos sem nenhuma cobertura, contrariando 0 que preconiza a lei.

Outras acusações se fundam no desrespeito às tradições e aplicação da medicina convencional, sem oportunizar a participação dos agentes de cura de origem indígena, desqualificando os saberes e práticas da medicina tradicional nos mais diversos grupos. Os indígenas que praticam as curas não são convocados para participar das ações de saúde e suas prescrições também não são valorizadas pelos profissionais de saúde ocidentais. Isso pode ser observado quando as condutas medicamentosas são prescritas, independente da adoção de tratamentos naturais e espirituais (ANDRADE; SOUSA, 2016).

É importante, no entanto, dialogar com a perspectiva da hegemonia da medicina ocidental, pois a rapidez com que os medicamentos produzidos pela indústria farmacêutica tendem a agir torna a Medicina Tradicional Indígena desinteressante e com eficácia questionada (DIEHL; LANGDON, 2015). 
Obviamente, os resultados dos medicamentos manipulados em laboratório, cujo extrato natural é potencializado e concentrado, são diferentes da apresentação dessas mesmas substâncias na natureza, não apenas nos benefícios, mas também nos efeitos adversos e nos perigos à saúde. Nesse sentido, o uso dos remédios industrializados é amplamente adotado, mesmo que os efeitos colaterais não sejam devidamente informados. Podem causar, além do uso indevido, a intoxicação, prejuízos físicos e dependência.

Ademais, a medicalização, reconhecida como prática de relacionar os aspectos da vida ao uso de medicamentos, promove essa percepção de que as pessoas precisam usar os remédios industrializados para afastar os mais diversos males, inclusive aqueles que podem ser reconhecidos como de ordem psicológica. Os índios, desta forma, não estão apartados dessa construção da modernidade, que pretende curar todas as dores e emoções indesejadas com remédios milagrosos.

Uma das justificativas apresentadas ao Ministério Público em resposta ao não atendimento em terras que ainda não estão demarcadas, é a aplicação da lei, que apenas orienta a construção de estruturas de Postos de Saúde Indígena em locais que já estejam, pelo menos, em tramitação para a legalização, sejam terras da União, tal como as outras áreas demarcadas. Embora o atendimento esteja, em tese, garantido, as estruturas de funcionamento podem ser improvisadas e sem as características técnicas adequadas (APIB, 2012).

O Estado afirma que 0 atendimento existe, porém precisa passar por ajustes para se adequar às demandas da população indígena, sobretudo dos grupos que estão em áreas limítrofes com outros países e as etnias nômades. Porém, a lei também é clara sobre 0 atendimento dos indígenas no território nacional. Desta forma, é necessária a atenção do que preconiza a lei Arouca, mesmo que para isto as equipes de saúde precisem fazer deslocamentos periódicos (CARDOSO, 2014).

Sobre o desrespeito às práticas tradicionais de medicina indígena, o Estado se posiciona contrariando as denúncias, afirmando que o planejamento e a implementação das políticas de saúde indígena estão de acordo com o previsto na lei e amparado pelas deliberações da CNS e CNSI (BERNARDES, 2011).

As pesquisas realizadas no âmbito da avaliação da SESAI e dos DSEl apontam uma dificuldade de ação dos profissionais de saúde, pois poucas universidades ${ }^{4}$ com cursos na área da saúde ofertam disciplinas e treinamentos que tratem das práticas alternativas, das práticas de cura dos povos indígenas e quilombolas e das ferramentas da Medicina Popular. Os recursos naturais aplicados nas práticas de cura e a espiritualidade não são devidamente abordados por essas avaliações, que funcionam como geradores das orientações para a atuação das equipes de saúde indígena. 
Os documentos normativos do Subsistema de Saúde Indígena são pródigos na repetição de princípios genéricos de ação (como preconizar, por exemplo, a articulação e o fortalecimento dos sistemas de medicina tradicional) que não se traduzem em atividades concretas nem nas programações anuais de atividades dos DSEI, nem nas práticas sanitárias das equipes (GARNELO, 2004, p. 13).

Em acréscimo, Diehl e Pellegrini (2014) afirmam que, mesmo com os esforços do movimento indígena e dos órgãos que atuam em defesa dessas populações, são comuns os relatos sobre dificuldades de adaptação dos profissionais contratados para atuar nas terras indígenas. Isso decorre das diferenças significativas na terapêutica e do uso de recursos naturais ou industrializados para a prevenção, e tratamento dos mais diversos transtornos. É presumível que uma parte dos profissionais que atuam nessas áreas não acatem o que preconiza a Lei Arouca, no que diz respeito ao uso de recursos difundidos nas etnias para a realização dos tratamentos de saúde e a participação dos mais diversos indígenas que estejam no rol de praticantes de cura, seja ela de ordem física, psíquica e/ou espiritual.

Esse debate é perene nas conferências locais e Estaduais em que estivemos presentes entre os anos de 2017 e 2019 e nos relatórios publicados pela FUNAI e SESAI dos últimos anos, pois na mesma medida em que o movimento indígena quer fortalecer as suas raízes, alguns agravos são, notadamente, conduzidos com maior efetividade e chance de sucesso com o uso de fármacos.

As reflexões sobre vida e morte e os significados desses dois estados da existência humana também são debatidos nesses eventos, pois a percepção do nascer, do adoecer e do envelhecer nas populações indígenas é visualizada como um ciclo. Ao contrário de como tem sido tratado pelas orientações sanitaristas, não é uma conduta comum a exclusão da enfermidade do espaço familiar e da delegação das perspectivas de prevenção e tratamento para os diplomados na saúde. Assim, fica a cargo dos indígenas, principalmente daqueles que têm os dons de cura, a efetividade de tratar dos doentes (DIEHL; LANGDON, 2015).

Nas oportunidades de participar de eventos da saúde indígena e contatar os participantes das conferências, fossem eles usuários, praticantes da cura ou membros das equipes de saúde, escutamos muitas defesas sobre o uso dos "remédios do mato", que tem sua eficácia e baixo custo. Isso diz respeito não apenas ao tempo de ação, mas à perspectiva de que não poderiam ser dissociados de outras práticas, como as que se referem aos tratamentos espirituais e aqueles em que mudanças de conduta diante da vida também são atribuídas para a melhoria dos sintomas.

Os remédios do mato são as raízes, folhas, frutos, flores, seivas e caules de plantas, banhas, carnes, ossos e órgãos de vários animais, uso de recursos minerais como pó de pedra e calcário. Os tratamentos espirituais envolvem rituais, rezas, danças e trabalhos espirituais, com a 
invocação de entidades, como os encantados, antepassados e forças da natureza para realizar a cura de diversos males.

O saber popular, desta forma, se evidencia como prática, inclusive na percepção sobre os efeitos adversos de algumas substâncias catalogados nas bulas dos fármacos, mas que não são devidamente esclarecidos para os usuários. Os efeitos, quase sempre desagradáveis, impactam na percepção de benefício do remédio, o que gera uma espécie de aversão (ATHIAS; MACHADO, 2001).

Já os jovens, talvez pelas influências que recebem com maior força de um mundo globalizado e com "emergências" para tudo ser rápido, enxergam o uso da medicina tradicional como algo ultrapassado. De acordo com os relatórios emitidos nas conferências de saúde indígena a adesão aos tratamentos de saúde com o uso de medicações industrializadas é maior entre os índios mais jovens. As referidas conferências são espaços de debates importantes para avaliar os desafios e os alcances dos programas de saúde indígena e as estratégias de ação para atingir as metas propostas pelo governo e atender as necessidades das etnias. Foram realizadas seis conferências, sendo a primeira o desdobramento da $8^{a}$ Conferência Nacional de Saúde, datada de 1986, e a última foi realizada em 2019.

Ainda que os questionamentos sobre ser indígena se configurem como uma prática em diversos espaços, se levarmos em conta a cultura como algo dinâmico e que recebe influências de outras culturas, essa análise perde o efeito. É comum que os indígenas sejam alvo de indagações sobre as mudanças nos seus hábitos de vida, de forma a serem observados romantizados, mesmo que o debate sobre as culturas e seu dinamismo já seja algo pacificado. Não diferente de outros povos, os índios acumulam conhecimentos de outros grupos, usam das tecnologias existentes e participam da teia de relações globalizadas (TEIXEIRA, 2012).

Dessa forma, 0 índio, tal como qualquer integrante de outro grupo étnico, modifica suas formas de enxergar a sua própria existência e recebe influências externas. Sua medicina, nesse sentido, da mesma forma que influencia a indústria farmacêutica, também é retroalimentada por ela, porém de forma mais efetiva e pragmática. Isso ocorre porque os saberes populares e o acesso aos recursos naturais e a seu uso medicinal são o mote para a realização de pesquisas cientificas para 0 desenvolvimento de fármacos. Porém, os indígenas como qualquer outro grupo, também recebem influência midiática, o que promove a percepção de que os medicamentos industrializados são mais efetivos no combate e controle de doenças do que os próprios compostos orgânicos, conhecidos por eles e presentes nos seus ecossistemas cujos extratos são usados para a fabricação de medicamentos. 
É incontestável que os laboratórios se baseiam em pesquisas cientificas para produzir remédios e se valem de uma indústria midiática para propagar os seus produtos. Da mesma forma que somos fortemente atingidos por isso, os índios não são diferentes, até porque os acessos às tecnologias também foram popularizados para eles, independentemente da situação precária em que se encontram, mesmo aqueles que estão em situação de vulnerabilidade (DIEHL; LANGDON, 2015).

Cardoso (2014) aponta que os aspectos balizadores da Medicina Tradicional Indígena não podem ser percebidos sem a crítica ao próprio sistema de saúde nacional, pois as Políticas Públicas de Saúde Indígena são parte do SUS, tratando os diferentes como diferentes, de acordo com a Constituição.

Assim, as equipes de saúde precisam lidar com duas variáveis importantes: aquelas questões que dizem respeito às peculiaridades dos povos indígenas e aquelas que dizem respeito aos direitos de todos os cidadãos e que são, também, obrigação do Estado, como o caso da vacinação, programas de erradicação de doenças transmissiveis e tratamento de doenças crônicas.

A crítica, dessa forma, se fundamenta na autodeterminação dos povos e na autonomia para escolha dos recursos de tratamento. De acordo com a normatização do SUS na Lei 8080/90, as equipes da atenção básica devem acompanhar e incentivar o uso de fármacos para o tratamento de doenças cuja notificação, inclusive, se dá de forma compulsória e cuja dispensação de medicamentos é realizada por uma regulação nacional. Assim, no caso de recusa para tratamentos como a hanseníase e a tuberculose, agentes do governo são acionados para acompanhamento dos casos, visitando os usuários do sistema e insistindo para a adesão (BECKER, 2009).

Mesmo compreendendo a emergência de um tratamento de doenças contagiosas ${ }^{5}$ e que podem causar agravos permanentes e a vulnerabilidade da saúde dos indígenas já diagnosticados com essas doenças, é inegável o desrespeito às culturas indígenas. Suas percepções sobre saúde e doença e seus métodos de cura são negligenciados, e a clínica convencional nos postos de saúde frequentemente não admite que outras formas de tratamento possam ser empregadas.

Por outro lado, as pressões sofridas pelas equipes de saúde para manter indicadores e registrar no sistema de informações do SUS as realizações nas aldeias, sob pena de terem baixas no repasse de recursos e redução de equipes, se apresentam como um desafio. Dessa forma, é possível compreender como as equipes lidam com as questões ora apresentadas, pois mesmo que uma orientação ideológica e legal se apresente como soberana, as perdas para as categorias profissionais e para o serviço ofertado ao restante dos indígenas pode ser fragilizado, caso os indicadores não estejam dentro do esperado para os investimentos destinados. 
Em outras palavras, fica difícil compreender em que medida é factível o respeito pelas tradições dos povos indígenas, se nem mesmo os aspectos de sua saúde podem ser tratados com os recursos adotados pelas etnias.

O grande desafio das políticas públicas de saúde indígena é atrelar duas formas distintas de conduzir o adoecimento e o reestabelecimento da saúde, sem ferir os preceitos estabelecidos na lei, que orienta os recursos para tratar das diversas demandas para os povos indígenas. Assim, as equipes de saúde precisam conhecer os recursos locais e conduzir as suas práticas, agindo sem coagir os índios a optarem pelas suas formas de tratamento (DIEHL; PELLEGRINI, 2014).

Mesmo que a orientação se constitua assim, na medida em que a sistematização dos tratamentos de doenças com notificações compulsórias seja também uma espécie de preferência nas estratégias do SUS, pode-se encontrar claramente uma hierarquia de prioridade das orientações gerais em detrimento das orientações especiais estabelecidas para os grupos com direitos diferenciados.

Porém, existem outras questões que precisam ser avaliadas na situação dos povos indígenas. Independente dos mecanismos de cura instituídos pela medicina ocidental, persistem saberes e práticas de saúde disseminados pelas diversas etnias, que não podem ser desqualificados, pois se fundamentam em uma lógica terapêutica desenvolvida pelos povos indígenas. Os efeitos dos remédios, das rezas e dos rituais são efetivos para a prevenção, tratamento e cura de várias doenças e, durante muito tempo, foram os únicos recursos que os índios tinham para resolver as mais diversas demandas de saúde (ANDRADE; SOUSA, 2016).

Nesse sentido, se faz de extrema importância refletir sobre como a saúde indígena é conduzida pelo poder público e a sua real aplicabilidade, tanto no respeito à medicina tradicional das mais diversas etnias como no atendimento integral em terras demarcadas ou não.

\section{CONCLUSÃO}

Este artigo acentua que o franco descumprimento do que preconiza a legislação sobre Políticas Públicas de saúde Indígena é recorrente. As diversas publicações analisadas denunciam 0 descaso do governo em realizar o que está previsto na legislação e que se configura como direito garantido.

Mesmo que as ações em saúde existam, o desrespeito à cultura e o despreparo dos profissionais de saúde para atender as demandas específicas das diversas etnias é recorrente. Aliada à dificuldade de pessoal qualificado, a oferta de serviços ainda é escassa. Ademais, os recursos utilizados para cura, que são os recursos também explorados pela indústria farmacêutica, não são 
devidamente valorizados pelos profissionais de saúde e pelo próprio governo. Essa afirmação decorre da atribuição aos indígenas da mesma circunstância do restante da população quanto à notificação compulsória das doenças e o tratamento padronizado com fármacos industrializados.

Desse modo, sem admitir alternativas possíveis dentro da vasta gama de recursos de que os povos indígenas são conhecedores, o governo desqualifica esse saber, dando primazia ao conhecimento do modelo biomédico que impera na formação dos profissionais da saúde.

Além disso, justificada pelas dificuldades operacionais e pelo sucateamento dos órgãos que atendem as causas indígenas, a saúde e os demais direitos garantidos, a realidade é que a oferta de atendimento e os indicadores de saúde são piores quando comparados a outros grupos, estando mais vulneráveis ao adoecimento.

Ainda que o desenho do sistema de saúde seja democrático e, teoricamente, cidadão, os povos indígenas não recebem 0 atendimento de qualidade que necessitam. Não obstante as deliberações sobre a saúde sejam compartilhadas e que os agentes de saúde indígena atuem como grandes aliados, ainda há muito que avançar para acatar o que está na legislação.

A causa indígena não se configura como uma prioridade do governo, pois os esforços para atender as suas necessidades mais básicas praticamente não existem e não são reconhecidos pela população brasileira como legítimos. Isso pode ser decorrente da própria ação do governo, que não adota medidas reais para a proteção das terras indígenas e dos povos, deixando-os em situação de risco e sujeitos aos mais variados tipos de violências.

\section{REFERÊNCIAS}

ANDRADE, João T.; SOUSA, Carlos Kleber Saraiva de. Práticas indígenas de cura no Nordeste brasileiro: discutindo políticas públicas e intermedicalidade. Anuário Antropológico, n. II, p. 179-204, 2016.

ARAÚJO, R. S. et al. Política Nacional de Atenção à Saúde Indígena no Brasil: dilemas, conflitos e alianças a partir da experiência do Distrito Sanitário Especial Indígena do Xingu. 2012.

ARTICULAÇÃO DOS POVOS INDÍGENAS DO BRASIL - APIB. Carta da comunidade GuaraniKaiowá de Pyelito Kue/Mbarakay para o Governo e Justiça do Brasil, 2012. Disponível em http://www.apib.org.br/2012/. Acesso em: 10 abr. 2020.

ATHIAS, R.; MACHADO, M. A saúde indígena no processo de implantação dos Distritos Sanitários: temas críticos e propostas para um diálogo interdisciplinar. Cadernos de Saúde Pública, v. 17, p. 425431, 2001.

BECKER, S. G. et al. Dialogando sobre o processo saúde/doença com a Antropologia: entrevista com Esther Jean Langdon. Revista Brasileira de Enfermagem, v. 62, n. 2, p. 323-326, 2009. 
BEM, I. P. Observatório da Saúde no Legislativo: as proposições em saúde no âmbito do Congresso Nacional (2011-2012). 2014.

BERNARDES, A. G. Saúde indígena e políticas públicas: alteridade e estado de exceção. InterfaceComunicação, Saúde, Educação, v. 15, p. 153-164, 2011.

BRASIL. Constituição (1988). Constituição da República Federativa do Brasil. Brasília, DF, Senado, 1998.

. Fundação Nacional de Saúde. Política Nacional de Atenção à Saúde dos Povos Indígenas. $2^{a}$ ed. Brasilia: Fundação Nacional de Saúde, 2002. 40 p.

. Lei $n^{0} .9 .836$ de 23 de setembro de 1999. Acrescenta dispositivos à Lei 8.080 de 19/09/1990, instituindo o subsistema de atenção à saúde indígena. Diário Oficial da União 1999; 24 set.

CARDOSO, M. D. Saúde e povos indígenas no Brasil: notas sobre alguns temas equívocos na política atual. Cadernos de Saúde Pública, v. 30, p. 860-866, 2014.

M. D. Políticas de saúde indígena no Brasil: do modelo assistencial à representação política. Langdon E.J., Cardoso M.D. (org.) Saúde indígena: políticas comparadas na América Latina. Florianópolis: Ed. da UFSC, p. 83-106, 2015.

CARLOS JR, E. A. Saúde e povos indígenas no Brasil: reflexões a partir do I Inquérito Nacional de Saúde e Nutrição Indígena. Cadernos de Saúde Pública, v. 30, p. 855-859, 2014.

CONSELHO INDIGENISTA MISSIONÁRIO - CIMI. A política de atenção à saúde indígena no Brasil: Breve recuperação histórica sobre a política de assistência à saúde nas comunidades indígenas. Edição revisada. Mato Grosso: CIMI, out. 2013. Disponível em: http://6ccr.pgr.mpf.mp.br/institucional/grupos-de-trabalho/saude/cartilha-sobre-saudeindigena-cimi. Acesso em: 10 abr. 2020.

DIEHL, E. E.; PELLEGRINI, M. A. Saúde e povos indígenas no Brasil: o desafio da formação e educação permanente de trabalhadores para atuação em contextos interculturais. Cadernos de Saúde Pública, v. 30, p. 867-874, 2014.

E. E.; LANGDON, E. J. Transformações na atenção à saúde indígena: tensões e negociações em um contexto indígena brasileiro. Universitas Humanística, n. 80, 2015.

FERREIRA, L. B.; PORTILLO, J. A. C.; NASCIMENTO, W. F. A Criação da Secretaria Especial de Saúde Indígena. Tempus Actas de Saúde Coletiva, v. 7, n. 4, p. 83-95, 2013.

FERREIRA, L. O. O desenvolvimento participativo da área de medicina tradicional indígena, Projeto Vigisus II/Funasa. Saúde e Sociedade, v. 21, p. 265-277, 2012.

GARNELO, L. Política de saúde dos povos indígenas no Brasil: análise situacional do período de 1990 a 2004. Porto Velho: UFRO; ENSP, 2004. 
L. Nutrição e alimentação em saúde indígena: notas sobre a importância e situação atual. In: GARNELO, L. e PONTES, A. L (org.). Saúde indígena: uma introdução ao tema. Brasília: Ministério da Educação Continuada, Alfabetização, Diversidade e Inclusão. Unesco, 2012.

L.; SAMPAIO, S. Organizações indígenas e distritalização sanitária: os riscos de" fazer ver" e" fazer crer" nas políticas de saúde. Cadernos de Saúde Pública, v. 21, p. 1217-1223, 2005.

GIOVANELLA, L. et al. Políticas e sistema de saúde no Brasil. SciELO-Editora FIOCRUZ, 2012.

INSTITUTO SOCIOAMBIENTAL. Povos indígenas no Brasil. Instituto Socioambiental, 2001.

MARTINS, André Luiz. Política de saúde indígena no Brasil: reflexões sobre o processo de implementação do Subsistema de Atenção à Saúde Indígena. 2013. 53 f. Dissertação (Mestrado em Saúde Pública) - Escola Nacional de Saúde Pública Sergio Arouca, Fundação Oswaldo Cruz, Rio de Janeiro, 2013.

MINISTÉRIO DA SAÚDE (BR). Conselho Nacional de Saúde. $5^{\text {a }}$ Conferência Nacional de Saúde Indígena: relatório final. Brasília: Minis. da Saúde, 2015.

MOURA, Bianca Coelho. Da estruturação a (r) evolução: o controle social indígena pós-criação da Secretaria Especial de Saúde Indígena. Tese de Doutorado, UNB, 2016.

NAÇÕES UNIDAS. Declaração das Nações Unidas sobre os Direitos dos Povos Indígenas. Rio de Janeiro, 2008 UNIC/ Rio/ 023, Mar. 2008.

SANTOS, R. V et al. Saúde dos povos indígenas e políticas públicas no Brasil. Políticas e Sistema de Saúde no Brasil. Rio de Janeiro: Fiocruz, p. 1035-56, 2008.

SMANIO, G. P. Legitimidade jurídica das políticas públicas: a efetivação da cidadania. $\mathbf{O}$ direito e as políticas públicas no Brasil. São Paulo: Atlas, 2013.

SOUZA, C. M. "Estado do campo" da pesquisa em políticas públicas no Brasil. 2003.

SOUZA, K. L. Avaliação normativa da gestão da política nacional de atenção à saude dos povos indígenas: um estudo de caso no distrito sanitário especial indígena da Bahia. 2017.

TEIXEIRA, C. C. A produção política da repulsa e os manejos da diversidade na saúde indígena brasileira. Revista de Antropologia, p. 567-608, 2012.

ZALUAR, A. Exclusão e políticas públicas: dilemas teóricos e alternativas políticas. Revista brasileira de ciências sociais, v. 12, n. 35, 1997.

\section{Notas}

1 Não atender a uma demanda populacional pode ser reconhecida como uma política de governo.

2 Garante ao cidadão, independente de etnia, o acesso aos serviços ofertados. Desta forma, o índio tem direito ao SUS e a especificidades próprias de seus direitos diferenciados. 
3 O SUS é um sistema de abrangência nacional, que viabiliza o atendimento integral de todos os brasileiros em território nacional. A atenção prioritária é a primária, que visa a adoção de medidas de controle e prevenção de doenças, antes que se manifestem de forma agressiva. As atenções secundárias e terciárias também são oferecidas, mas a principal atuação é no campo da preservação da saúde e do atendimento de pacientes com doenças que requerem o acompanhamento para evitar o agravamento.

4 Embora os cursos de saúde não tenham conteúdos curriculares sobre os povos indígenas, os cursos de Magistério Intercultural Indígena, promovidos pelas Universidades Estadual e Federal do Ceará, contemplam a Medicina Tradicional Indígena.

${ }^{5}$ Atualmente os povos indígenas têm sofrido com a pandemia. As ações do MS não têm sido suficientes para poupar vidas, mesmo sendo pública a vulnerabilidade dos índios pelas condições de pobreza, violência e de baixa imunidade sanitária. $A$ Articulação dos Povos Indígenas do Brasil - APIB tem denunciado o crescente número de indígenas vítimas do Covid-19. 